\title{
From a Tactile Epistemology to the Ontology of Affect: Two Readings of Deleuze's Time-Image in Film and New Media Theory
}

\author{
Árpád Bak \\ Eötvös Loránd University (Budapest, Hungary) \\ $\mathrm{PhD}$ Program in Film, Media and Contemporary Culture \\ E-mail: arpadbak@gmail.com
}

\begin{abstract}
The paper compares how two theorists of media arts, Mark B. N. Hansen and Laura U. Marks, interpret the relation of Deleuze's time-image to corporeality. Both argue that some novel types of images - in film and media art - engage the body in new and also more intensive ways than traditional cinema did. While they remain committed to Bergson's theory of perception, their works offer different readings of how the Bergsonian concepts of Deleuze's film philosophy can be applied to new media: on the one hand, to the non-signifying, affective properties of Hansen's digital image in contemporary media arts, and on the other, to Marks's - in the last instance, memory-signifying - haptic image, which she discussed initially in connection with video art and experimental film. In New Philosophy for New Media (2004), Hansen asserts that "Deleuze's neo-Bergsonist account of the cinema carries out the progressive disembodying of the [body]", which "reaches its culmination in [...] what he calls the "time-image,"” and calls for "a rehabilitation of Bergson's embodied concept of affection." While Marks also offers some criticism on Deleuze, she suggests that his "theory of timeimage cinema permits a discussion of the multisensory quality of cinema," and undertakes to examine "how the body may be involved in the inauguration of time-image cinema." Besides arguing that both tendencies are present in Deleuze to varying degrees, I attempt to contextualize the divergences in their lines of thought by looking at the types of media and selection of works they examine, as well as the possible theoretical commitments that might guide these selective strategies.
\end{abstract}

Keywords: Deleuze’s time-image, digital, haptic image, affect, body, new media.

“[Deleuze’s] writings on cinema may be brought productively to works of which he was not aware or did not exist at the time of his writing. His cinematographic philosophy is always open to transformation, to producing new concepts. [...] I intend to make his theories think by bringing them into contact 
with new images" - wrote Laura U. Marks in her 2000 book Skin of the Film: Intercultural Cinema, Embodiment and the Senses, which offers an elaboration of the political implications of Deleuze's film philosophy as applied to diaspora experimental film and video art (26). For this end, she does not resort directly to what the French philosopher wrote about "modern political cinema," which he equated with third world and minority film in Cinema 2: The Time-Image (1985), but uses Deleuze's theory of time-image cinema to discuss "the multisensory quality of cinema" (Marks 2000, xiv) - a quality that intercultural works utilize to find new languages suitable for challenging official histories. ${ }^{1}$

Marks examines how the works of diaspora artists exploit our non-visual senses, such as touch, smell and taste, through the faculties of vision and hearing. She is especially interested in incomplete or - at least, seemingly non-signifying images, which she relates to the Deleuzian time-image. In Skin of the Film, she identifies the latter with images that "force the viewer to draw upon his or her subjective resources" (Marks 2000, 43), which in the case of intercultural film and video - unlike for Deleuze - are influenced by collective memories, deeply seated in the body: "If a viewer is free to draw upon her own reserves of memory as she participates in the creation of the object on screen, her private and unofficial histories and memories will be granted as much legitimation as the official histories that make up the regime of the cliché - if not more" (Marks 2000, 48).

Yet, these images - which Marks relates to what Deleuze calls fossils in Cinema 2 - mobilize not only the viewer's imagination, but, by various strategies, also his or her corporeal registers. It is partly through this focus on corporeality that Marks extends the notion of the Deleuzian fossil, connecting it to the social. To achieve this, Marks suggests a partial return to Bergson: "When discussing perception itself, Deleuze tends to suggest that individual perception is possible without recourse to collective memory. In contrast, I argue that the element of communal experience that is implicit in Bergson's theory of

1 Marks traces the idea that "intercultural cinema is fundamentally concerned with the production of new languages, and the difficult task of defining intercultural cinema rests in its emergent character" (2000, xiv) to Kobena Mercer, Trinh T. Minh-ha and Hamid Naficy. The works she looks at address sensoria different from the Western, ocularcentric configurations of the senses, to represent collective memories that are repressed in the traditional - that is, European and North American - narratives of history. However, in Cinema 2 Deleuze also pointed out the challenges that third world and minority cinema face in terms of selfrepresentation: "Sometimes the minority film-maker finds himself in the impasse described by Kafka: the impossibility of not 'writing,' the impossibility of writing in the dominant language. [...] The third world intellectual [...] has to break with the condition of the colonized, but can do so only by going over to the colonizer's side, even if only aesthetically, through artistic influences" (Deleuze 1989, 221). 
perception necessarily informs the process of cinematic spectatorship as well. Perception is never a truly individual act but also an engagement with the social and cultural memory" (2000, 62).

Marks also points out a similar tendency in Merleau-Ponty's work. She claims that despite the rather schematic examples Merleau-Ponty gives for embodied perception, his arguments suggest that "the experience of the body is informed by culture" (Marks 2000, 152), as exemplified by the recent interest of feminism and cultural anthropology on phenomenology. Marks finds Merleau-Ponty inspirative also because his phenomenology "did in fact inherit and expand Bergson's implication of perception in the body" $(2000,150)$. She considers it an important complement to the temporal orientation of Deleuze's theory, because MerleauPonty's work - she suggests - reintroduces an interest on the spatial relation between viewer and image. It is only in her discussion of the French phenomenologist that she offers a criticism on Deleuze similar to Hansen's: "Deleuze says, 'Give me a body, then,' but his interest is not in exploring how cinema relates to the bodies we have already been given" (Marks 2000, 150).

But this is rather an exception in her reading of Deleuze, in which she repeatedly emphasizes the relevance of the time-image to embodied perception. In New Philosophy for New Media (2004), Mark B. N. Hansen offers a more radical criticism on Deleuze, privileging Bergson for his treatment of affective embodiment. While Marks maintains that "for Deleuze [...] the time-image cinema does not abandon the body" (2000, 73), for Hansen, "Deleuze's neoBergsonist account of the cinema carries out the progressive disembodying of the center of indetermination [i.e. the body]. This disembodying reaches its culmination in the second volume of his study devoted to what he calls the 'time-image"” $(2006,6)$. These contradictory readings of Deleuze root in the different types of new images the two authors are interested in, corresponding to their wider theoretical agendas.

Hansen examines the digital image in a selection of new media art, which although he tends to speak generally about the category - seem to represent only a subset among various types of digital images. Although this version is itself diverse in terms of aesthetic or even technical properties, he suggests that, as a distinctive feature, they all rely on the creative capacities of bodily affect. In a review of Hansen's book, Dutch artist René Beekman criticizes him for "his fairly typical choice of artworks" $(2005,355)$. According to Beekman, in order to put bodily affection into the centre, "all new media artwork [the author] refers to either involves physical, bodily, haptic contact between the artwork 
and the visitor [...], are representations of the human body [...] or are literal representations of the bodily expression of emotions [...]" $(2005,355) .^{2}$

Among the exceptions might be Craig Kalpakjian's works (Hall [1999], HVAC III [2000], Duct [1999]) that present corporate spaces from perspectives that are - to use Hansen's Deleuzian term - incompossible with the human experience, "in order to highlight the extraction of the human presence from the artificial [...] spaces he renders" (Hansen 2006, 211). Works like these echo how Deleuze describes the prefiguration of the any-space-whatever, one of the two signs of the affection-image, in experimental film: "If the experimental cinema tends towards a perception as it was before men (or after), it also tends towards the correlate of this, that is, towards an any-space-whatever released from its human co-ordinates" $(2009,125)$. While, however, for Deleuze, the resulting "space without reference points" $(2009,125)$ retains potentialities for perception, ${ }^{3}$ Hansen argues that its digital counterpart instead "catalyze[s] the production of a space within the body that is without direct (perceptual) correlation with the non-spaces [it] represent[s]" $(2006,213)$, relying less on the faculty of perception than on the affective capacities of the body.

Thus, for him, the digital image marks a "paradigm shift" in aesthetic culture: "a shift from the dominant ocularcentrist aesthetic to a haptic aesthetic rooted in embodied affectivity" (Hansen 2006, 12). Here, the latter concept emerges as an alternative not only to visuality but to perception in a more general sense following Gilbert Simondon's distinction, Hansen describes perception as a faculty of the individuated being, while affectivity is a "mode of bodily experience which mediates between the individual and the preindividual" $(2006,8) .{ }^{4}$ Hansen later, paraphrasing artist Bill Viola, also offers a definition of

2 This summary is rather simplified, but the assertion is correct that Hansen examines a limited selection of images. Beekman also professes that the author frees the image of its own materiality, which disregards examples like Alba D’Urbano's Touch Me (1995). This interactive installation invites the viewer literally to touch the screen, according to Hansen, engaging him or her with its "informational materiality" (Hansen 2006, 141).

3 "Nothingness is itself diverted towards that which comes out of it or falls back on it, the genetic element, the fresh or vanishing perception, which potentialises a space by retaining only the shadow or the account of perception" (Deleuze 2009, 125).

4 In critical theory a turn to affect was inaugurated in the mid-1990s, influenced by Spinoza's naturalist philosophy (Brian Massumi) and Silvan Tomkins's psychological theory on affects (Eve Sedgwick, Adam Frank). The meaning of affect in this context has also been differentiated from emotions recently and refers to preconscious, visceral bodily reactions that are - at least, seemingly - outside the realms of language, meaning and signification. According to Massumi, "emotion and affect [...] follow different logics and pertain to different orders. An emotion is a subjective content, the sociolinguistic fixing of the quality of an experience which is from that point onward defined as personal" (2002, 27-28). However, prepersonal 
affect that more clearly reflects the neuroscience-inspired language of affect theory: "affectivity is [...] something that passes through the body and that can only be felt, often at a speed beyond and of a magnitude beneath the perceptual thresholds of the unaided human perceptual apparatus" $(2006,159)$.

A forceful example for this "affective bodily response" (Hansen 2006, 202) might be Hansen's description of Robert Lazzarini's sculptural installation skulls (2000), from the 2001 exhibition BitSreams at Whitney Museum of American Arts, New York. Lazzarini mounted four 3D-printed anamorphic skulls, one apiece on the four walls of an exhibition room, creating a warped, topological space - if seen as part of a single continuum - that refuses to translate into a coherent visual logic from any single perspective. Yet, Hansen asserts that the affective process Lazzarini's work catalyses "creates a place within our bodies" $(2006,203)$, which is not altogether analogous to the spectacle. In his account, "our visual faculties are rendered useless and we experience a shift to an alternate mode of perception rooted in our bodily faculty of proprioception" $(2006,202){ }^{5}$

But, more often, Hansen describes affectivity as "a phenomenological modality in its own right" $(2006,204)$ rather than a mode of perception, and attributes the digital image with the capacity of "liberation of affectivity from perception" (2006, 205). Therefore, this type of image is seen more like a process, with the affective body at its centre, instead of being simply framed by a technological

as affect is, it is not altogether outside history: "Intensity [i.e. affect] is asocial, but not presocial - it includes social elements but mixes them with elements belonging to other levels of functioning and combines them according to different logic" (Massumi 2002, 30).

5 Just as Deleuze's affection-image introduced a new type of space into cinema with the any-space-whatever (ASW), for Hansen, skulls also represents a novel space, specific to the digital image. But unlike the fragmented spaces of the cinematic ASW, which Deleuze partly derives from post-war urban landscapes, Hansen claims its digital counterpart lacks such real-world equivalent: "the very existence of an 'original' correlation between the cinematic ASW and empirical space means that there is a preexistent analogy between the human experience of space and the cinematic ASW. It is precisely such a preexistent analogical basis that is missing in the case of the digital ASW. Unlike the cinematic ASW, this latter emerges from the bodily processing of a spatial regime that is, as it were, radically uninhabitable-that simply cannot be entered and mapped through human movement" (Hansen 2006, 208-209). However, even if the digital image finally manifests in the form of a "postvisual" space lived by the body, he notes that the perspectival distortion of skulls "can be realized (and corrected) - and that 'makes sense' visually - only within the weird logic and topology within the computer" (Hansen 2006, 202). Using the data-space of the computer as a historical reference point for the digital image, or at least its visual incarnation, might remind of Lev Manovich's concept of cultural transcoding, described by the latter theorist as "the process of 'conceptual transfer' from the computer world to culture at large" (Manovich 2001, 47). 
apparatus. Hansen dismisses Deleuze for supposedly not paying attention to the embodied nature of perception in Bergson's philosophy when - by what Hansen calls a transformative appropriation - he applies it to modern cinema. ${ }^{6}$ As quoted before, Hansen sees it a "progressive," gradually unfolding tendency in Deleuze's work, in which the body is reduced to the sensorimotor logic of the movement-image in Cinema 1 (1983), while the time-image in the subsequent volume (Cinema 2, 1985) reflects the workings of the brain.

Thus, he is interested in new media works that relocalize "the time-image from a purely mental space [...] to an embodied negotiation with the interstice or between-two-images that necessarily takes place in the body-brain of each specific viewer-participant" (Hansen 2006, 246) and "expose the fundamental limitation of Deleuze's cinema of the brain: its investment in an isomorphism between the time-image and the contemporary brain" (Hansen 2006, 248). ${ }^{7}$ At a later point, Hansen also finds Bergson's conception of the body somewhat limited. While in Bergson's theory embodied perception subtracts pre-existing images from its environment, which "display [...] the eventual or possible actions of [the] body" (Bergson 1991, 22), Hansen goes further and says that in the digital age it is the body that generates images from pure, formless information. That is, "beneath any concrete 'technical' image or frame lies [...] the framing function of the human body qua center of indetermination” (Hansen 2006, 8).

For Hansen, this contemporary body, partly brought about by the digital technologies, re-establishes the possibility of belief in the world. This belief was also a central problem for Deleuze, who saw the break in the sensorimotor link, associated with the emergence of time-image, accompanied by a more general disjunction of man and world. However, he shows less interest in the fact that Deleuze also saw the body as a substitute for the loss of the ability of the timeimage to react: "What is certain is that believing is no longer believing in another world, or in a transformed world. It is only, it is simply, believing in

6 It is beyond the scope of this paper to evaluate Deleuze's understanding of Bergson's philosophy of perception. The point of interest is rather how the timeimage in Cinema 2 itself relates to the body and affectivity, as understood in contemporary critical theory. Similarly, comparing the corporeality of the two cinema books against the wider context of Deleuzian thought exceeds the aims of the present endeavour.

7 He offers this interpretation of Douglas Gordon's works, which he assumes to involve the affective capacities of the body by strategies like temporal deceleration, temporal discordance or perceptual shift. For example, 24-Hour Psycho (1993) uses Alfred Hitchcock's film Psycho (1960) as a found footage, projected on a screen at a 2 frames-per-second speed, instead of the normal $24 \mathrm{fps}$. According to Hansen, the slowly changing images subject the viewer to a state of "affective anticipation" (Hansen 2006, 244), an intense physiological experience that directs the attention to the properties of the lived now. 
the body. It is giving discourse to the body, and, for this purpose, reaching the body before discourses, before words, before things are named: the 'first name' and even before the first name" (Deleuze 1989, 172-173). ${ }^{8}$

Although Deleuze indeed notes in Cinema 2 that "the essence of cinema [...] has thought as its higher purpose, nothing but thought and its functioning" (1989, 168), he later adds that "[i]t is through the body (and no longer through the intermediary of the body) that cinema forms its alliance with the spirit, with thought" $(1989,189)$. His study of the time-image also describes how the emergence of a new, acentred scientific model of the brain transformed the tradition of intellectual film: the images of this new regime replace those that like, for example, Eisenstein's dialectical montage - force us to think with ones that instead, as anticipated by Antonin Artaud's film theory, reveal a "powerlessness at the heart of thought" (Deleuze 1989, 166). The resulting "new image of thought" follows an irrational, probabilistic logic, in its formal attributes defined by elements such as the point-cut, the relinkage and the black or white screen.

The "purely optical and sound situations" (Deleuze 1989, 4) - or "purely visual situations" $(1989,169)$ - associated with the time-image break the link with the sensorimotor body of classical cinema, ${ }^{9}$ but they do not necessarily lose all ties to the body. ${ }^{10}$ In spite of Deleuze often describing the time-image as optical, Marks associates the time-image with haptic vision, assigning a cognitive function to it that, though based on a different mechanism, has a similar effect to montages in classical intellectual cinema: "Haptic images are actually a subset of what Deleuze referred to as optical images: those images that are so 'thin' and unclichéd that the viewer must bring his or her resources of memory and imagination to complete them. The haptic image forces the viewer to contemplate the image itself instead of being pulled into narrative. [...] Accordingly, the optical image in [Alois] Riegl's sense corresponds to Deleuze's movement image, as it affords the illusion of completeness that lends itself to narrative.” $(2000,163$.

8 Deleuze saw a deep-going connection between cinema and belief, either religious or revolutionary. Christian Haines suggests a direct political reading of the body that emerges in Cinema 2 as a new basis for the belief in the world, yet the quoted passage seems to refuse both the transcendental and the revolutionary ("believing in another world, or in a transformed world" [Deleuze 1989, 167]).

9 They also expose the limits of thought by putting the viewer "in the psychic situation of the seer, who sees better and further than he can react, that is, think" (Deleuze 1989, 170).

10 Deleuze also proclaims that "the time-image does not imply the absence of movement (even though it often includes its increased scarcity) but it implies the reversal of the subordination; it is no longer time, which is subordinate to movement; it is movement, which subordinates itself to time” (Deleuze 1989, 271). 
For example, Roula Haj-Ismail's video I Wet My Hands Etched and Surveyed Vessels Approaching Marks Eyed Inside (1992), juxtaposes close-up images of bodily scars and war-torn walls in Lebanon with the camera "caressing the buildings, searching the corners of shutters and stone-latticed windows like folds of skin" (Marks 2000, 157). These sequences challenge the traditional representations of a post-bombings Beirut by focusing on surfaces and small details, which - accompanied by a poetic voiceover - evoke collective memories in a personal way. Some of the works Marks examines use blurred images to counter the Western, ocularcentric way of knowing the other, which often turn him or her into a pure, objectified spectacle, subsuming visual control over indigenous cultures. ${ }^{11}$ In others, knowledge and memory is embodied in physical objects: in Marta Rodriguez and Jorge Silva's Love, Women and Flowers (1988) carnations remain the markers of Columbian women's labour and health-damaging exploitation, from which the plants get alienated in the shopwindows of European florists, still looking freshly-cut. Rea Tajiri's History and Memory: For Akiko and Takashige (1991) interrogates a piece of tar paper taken from a WWII internment camp for Japanese-Americans in the United States to give up repressed historical memories.

Deleuze himself refers to Riegl's concept of the haptic gaze in his description of how the close-ups of hands construct a tactile space in Bresson's Pickpocket (1959), ${ }^{12}$ but Marks emphasizes that haptic visuality extends further than the direct representation of touch, the latter addressing the senses indirectly, through an intermediary body, while keeping the viewer at a distance from the image $^{13}(2000,171)$. Shauna Beharry's video Seeing is Believing (1991) is a good illustration of this difference. The work is based on a single photo of the IndianCanadian artist, wearing her deceased mother's sari to establish a relationship with her memory in a more intimate way than looking at a photo would allow.

11 Some of the works achieve the same effect by using incongruous soundtracks that undermine visual representations. Such is the case with a sequence in John Akomfrah's experimental documentary Handsworth Songs (1986), in which archive footage showing the arrival of West Indies immigrants to Britain, looking into the camera with a cheerful, optimistic expression, is offset by brooding, melancholic tunes. Marks relates these deliberate mismatches to the paradoxical relations between past and present in the time-image, also calling into question the truth behind representation, which Deleuze calls - borrowing the term from Leibniz incompossibility.

12 "The hand doubles its prehensive function (of object) by a connective function (of space); but, from that moment, it is the whole eye which doubles its optical function by a specifically 'grabbing' [haptique] one, if we follow Riegl's formula for indicating a touching which is specific to the gaze" (Deleuze 1989,13).

13 For Hansen, the classical sensorimotor scheme seems to confirm to Riegl's optical mode of vision, which he also relates to Adolf von Hildebrand's far-viewing (Fernbild), as opposed to the haptic mode or close viewing (Nahsicht) (Hansen 2006). 
With an extreme close-up of the cloth's folding texture, the image itself challenges the autonomy of vision and engages the tactile senses. Ironically, a still from the video in the book shows Beharry's hand touching the garment over her skin, but for Marks, it is the sight of the textile's material that turns the video into a haptic medium: "I have been brushing the (image of the) fabric with the skin of my eyes, rather than looking at it" $(2000,127)$.

Hansen also remarks the passage on Pickpocket in Cinema 2, but challenges it for another reason: he finds Riegl's version of hapticality too confining because it is reduced to merely a mode of vision, instead of differentiating affection from vision, or "displacing the tactile-haptic from the image to the body" $(2006,225)$. With this strong emphasis on the autonomy of affection, it is not the sensorimotor body of classical cinema that Hansen is looking for to return with the digital image. He writes that "the body that surfaces in the age of the digital revolution the very body that forms the 'object' of contemporary neuroscience - has scant little in common with the associational sensorimotor body of Deleuze's Cinema 1" (Hansen 2006, 7). What makes this body different from the one associated with movement-image is its affective disposition, that is, "its capacity [...] to experience itself as 'more than itself' and thus to deploy its sensorimotor power to create the unpredictable, the experimental, the new" (Hansen 2006, 7). ${ }^{14}$

Although Hansen articulates in his introductory chapter to New Philosophy for New Media that - quoting Brian Massumi - affectivity is intrinsically connected to motion, some of the works he later examines seem to trigger affective bodily responses not by the representation or the production of physical movement in space. For example, the warped space Hansen assigns to Lazzarini's skulls "refuses to map onto [the viewer's] habitual spatial schematizing" $(2006,200)$ and the affective space that it creates within the body is "unaccompanied by any perceptual correlate"15 $(2006,206)$. Some of the images that Hansen discusses in relation to digital faciality generate an affective response in the viewer by means of facial close-ups. There are similar long takes of close-up shots and tableau

14 While the time-image is most often associated with the emergence of a new conception of the brain, Christian Haines also argues that it inaugurates a new kind of corporeality. In his political reading of Deleuze, he identifies the sensorimotor link in Cinema 1 with the logic of capitalism, which makes the movements of the body calculable and controllable, while in Cinema 2 "the body emerges as incomplete, as the seed, and not actual emergence, of another world" (Haines 2011, 116). To an extent, this echoes Hansen's view of the body as a source of indeterminacy, which, for him, serves as a new basis for belief in the world although Hansen is less interested in finding direct political implications of what he calls the contemporary body.

15 Hansen connects this inner, affective space to Bergson, who "postulates such a sensorimotor space within the body. As he sees it, affection is itself a kind of action distinct from perception: 'real' rather than 'virtual' action” $(2006,225)$. 
vivant-like scenes in Bill Viola's digital video series Passions (2000-2001), shot at a 384 frame-per-second speed and played back extremely slowly, which Hansen in its relation to temporality - considers an example of "the movement of new media art beyond cinema" $(2006,264)$.

Hansen introduced the notion of the Digital Facial Image (DFI) as a counterpoint, in many ways, to the Deleuzian affection-image, a form of movement-image discussed in Cinema 1, which foreshadows the time-image of the subsequent volume. In Hansen's account, the affection-image transcends its ties with the body by "tearing the image away from its spatiotemporal localization" (2006, 137), which refers to the "change of dimension" (Deleuze 2009, 98) that Deleuze - influenced by how Béla Balázs defined the facial closeup - attributed to this type of image: "The affection-image, for its part, is abstracted from its spatio-temporal co-ordinates which would relate it to a state of things, and abstracts the face from the person to which it belongs in the state of things" (Deleuze 2009, 100). The fact that Deleuze severs the ties of the facial close-up not only from sensorimotor action but also from its spatially embedded character is enough for Hansen to claim that it liberates affect from the body, ignoring that for Deleuze affect "surges in the centre of indetermination" (2009, 67). Marks, on the other hand, remarks that the "disengagement of affective response from action" holds a significance in understanding "how the body may be involved in the inauguration of time-image cinema" $(2000,28)$.

The comparison of the affection-image with the post-Deleuzian DFI requires a differentiated understanding of the body. When Hansen points out that the affection-image deindividualized the body while the DFI "carries out [its] fundamental reindividuation" (2006, 132), he is not talking about the same body: the represented body in the first part of the statement is substituted with that of the viewer in the second. Although he later elaborates that in the case of digital affection-images "the emphasis is transferred from the image to the embodied response it catalyzes" (Hansen 2006, 138), in many of his references on the body, its status remains ambiguous: the narrative of the "cinematic detachment of affect from the body" (Hansen 2006, 137) or "the disembodying of affect" (Hansen 2006, 148) is thus staged against that of "a reinvestment of the body as the rich source of meaning" (Hansen 2006, 131).

The DFI refers to digital and robotic interfaces that seduce the viewer to interact with them, but, short of a consensual, codified protocol for communication, the encounter will resist signification and instead triggers affective processes in the body "through which we open ourselves to the 
experience of the new" (Hansen 2006, 133). ${ }^{16}$ Thus, no matter how frustrating the situation gets by its challenge to a semantic understanding, its rootedness in affectivity makes it fundamentally benign for Hansen because - it is one of his key arguments - affect is the source of human creativity: "Not only it is a modality of experience in its own right, but it is that modality - in contrast to perception - through which we open ourselves to the new" (Hansen 2006, 133, emphasis added). This latter aspect of affect is not inevitably in conflict with how Deleuze himself thinks of it, for whom 'the affect is the 'new,' and new affects are ceaselessly created, notably by the work of art" (Deleuze 2009, 101).

If this newness ultimately originates in the viewer, Hansen's understanding of affect might be not irreconcilable with Deleuze's, even if the taxonomic endeavour in Cinema 1 and 2 puts more emphasis on the images themselves than on the responses they evoke. Hansen accuses Deleuze with bereaving affect of the autonomy Bergson furnished it with, by making it a subcomponent of perception. Yet, the following passage from Deleuze makes it possible to regard the difference between affect and perception one of kind rather than degree:

"[Affection] surges in the centre of indetermination, that is to say in the subject, between a perception that is troubling in certain respects and a hesitant action. It is a coincidence of subject and object, or the way in which the subject perceives itself, or rather experiences itself or feels itself 'from the inside' (third material aspect of subjectivity). [...] It relates movement to a 'quality' as lived state (adjective). Indeed, it is not sufficient to think that perception - thanks to distance - retains or reflects what interests us by letting pass what is indifferent to us. There is inevitably a part of external movements that we 'absorb,' that we refract, and which does not transform itself into either objects of perception or acts of the subject; rather they mark the coincidence of the subject and the object in a pure quality." (Deleuze 2009, 67-68.)

Although the first sentence indeed suggests that affect is a corollary of perception, as the reasoning unfolds, it more and more appears as a function in its own right, reacting to impulses that are outside the realm of natural perception. Regarding it a "coincidence of subject and object" is also in accord with Hansen's perceiving affection as a "medium of contact," fulfilling a "suturing function" $(2006,141)$ between the image and the human body. Deleuze also endows affect with autonomy when observing that it "is impersonal and is distinct from every individuated state of things: it is none the

16 In an account of such a work, British collective Mongrel's Colour Separation (1998), "the result is the experience of an ever mounting affective excess that emerges in the body of the viewer-participant as a kind of correlate to - perhaps even a recompense for - the incongruity between the image of a face and the voice used to narrate its story" (Hansen 2006, 151). 
less singular, and can enter into singular combinations or conjunctions with other affects" (Deleuze 2009, 101).

Marks does not use the notion of affect in her work extensively, but - as seen before - she would not be likely to endorse Hansen's assertion that Deleuze reduced "bodily affection to one specific permutation of the movement-image (the affection-image)" (Hansen 2006, 134). In Skin of the Film she suggests that the time-image does engage the body, even if the image is abstract, nonsignifying. ${ }^{17}$ Marks points out that the absence of image characterizing modern cinema - "a black or white screen, underexposed or snowy image" $(2000,42)-$ also holds the capacity to restore the belief in the world by offering a "cinema of constitution," devoted to the constitution of bodies. Deleuze writes this first in connection with Philippe Garrel, but later also adds that Jean-Louis Schefer saw cinema more fundamentally connected to the body than theatre due to this constitutive nature: "The object of cinema is not to reconstitute a presence of bodies, in perception and action, but to carry out a primordial genesis of bodies in terms of a white, or a black or a grey (or even in terms of colours), in terms of a beginning of visible which is not yet a figure, which is not yet action. [...] Cinema thus coincides with its own essence: a proceeding, a process of constitution of bodies from the neutral image, white or black, snowy or flashed. The problem is not that of a presence of bodies but that of which is capable of restoring the world and the body to us on the basis of what signifies their absence. The camera must invent the movements or positions which correspond to the genesis of bodies, and which are the formal linkages of their primordial postures." (1989, 201-202.)

This process of becoming is just one aspect of what Deleuze calls the cinema of the body, one of the two major traditions of the time-image, ${ }^{18}$ the other being the cinema of the brain. Their modes of operation are, of course, not independent from each other - an interest in the building elements of thought and perception also defines the cinema of the brain: "Thought is molecular. Molecular speeds make up the slow beings that we are. As Michaux said, 'Man

17 This tendency is already present in Cinema 1, in which the close-up - one of the two signs of the affection-image - does not have to represent the face to take on a facial (i.e. affective) quality, while the other sign, the any-space-whatever precipitated "non-human affects" (Deleuze 2009, 113). According to Deleuze, the second type is "more subtle than the first, more suitable for extracting the birth, the advance and the spread of affect" (Deleuze 2009, 113).

18 Cf.: "[Antonioni's] work, in a fundamental sense, passes through a dualism which corresponds to the two aspects of the time-image: the cinema of the body, which puts all the weight of the past into the body, all the tiredness of the world and modern neurosis; but also a cinema of the brain, which reveals the creativity of the world, its colours aroused by a new space-time, its powers multiplied by artificial brains" (Deleuze 1989, 197). 
is a slow being, who is only made possible thanks to fantastic speeds.' The circuits and linkages of the brain don't preexist the stimuli, corpuscles, and particles [grains] that trace them" - Deleuze commented in an interview, suggesting an analogy with the idea that “cinema isn't theater; rather, it makes bodies out of grains" (Bonitzer 2000, 366).

This filmic tradition also uses non-visual resources, such as sound to create the body, while - as if it were a substitute for the sensorimotor action-reaction it extends the function of the body beyond the everyday: drawing on experimental film, it becomes ceremonial, incorporating new temporal structures and constructing new types of spaces. The "gests" of the body in modern cinema - Deleuze here uses an adapted version of Brecht's theatrical term - magnify the lived present in a similar way as the video works in Bill Viola's Passages-series, focusing on the unnoticed interstices in perception: "What is important is less the difference between the poles than the passage from one to another, the imperceptible passage of attitudes or postures to gest. [...] What we call gest in general is the link or knot of attitudes between themselves, their coordination with each other, in so far as they do not depend on a previous story, a pre-existing plot or an action image. On the contrary, the gest is the development of attitudes themselves, and, as such, carries out a direct theatricalization of bodies, often very discreet, because it takes place independently of any role.” (Deleuze 1989, 192.)

In an interview, Viola sums up the purpose behind his work in a similar manner: "I was most interested in opening up the spaces between the emotions. I wanted to focus on gradual transitions - the idea of emotional expression as a continual fluid motion. This meant that the transitions, the ambiguous time when you shift from being happy to sad, is just as important as the main emotion itself" (quoted in Hansen 2006, 612-613).

These ambiguous moments are important for Hansen and Marks, because the intervals they open suspend the clichés that underlie perception. This disruption of habituality also holds the possibility of social change, a concern present in the two authors' work with different intensities. In Marks's case, it is the "hegemonic form of perception" $(2000,42)$ aimed at maintaining power relations that is challenged, while Hansen offers criticism on seeing contemporary media as instruments of reproducing "the universalizing logic of capitalism" $(2006,23)$ or - as he refers to it in another text - "the industrialization of consciousness" (2009, 301). To pursue their aims, they resort to two different conceptions of corporeality. Marks, who is looking for hidden histories, enunciates that "I am exploring sense experience in cinema not to seek a primordial state of sensory innocence, but to find culture within the body" $(2000,152)$. This recalls the temporality Deleuze ascribes to the cinema of the body, "which puts all the 
weight of the past into the body" $(1989,197)$. For Hansen, on the contrary, the contemporary body draws on a sensory innocence as it encounters the digital image, opening towards an indefinite future rather than the past. Thus, Hansen's concept of new media art is grounded in a contingent ontology, similarly to the cinema of the brain, which, for Deleuze, "reveals the creativity of the world, its colours aroused by a new space-time, its powers multiplied by artificial brains" (1989, 197).

However, both traditions of modern cinema, at least as Deleuze understands them, are closer to the universalist position that Hansen embraces. Marks finds culture within the body to explore the political implications of Deleuze's film theory, partly by - similarly to how Elizabeth Grosz challenges the dichotomy of nature and culture - recoursing to scientifically inspired theories like that of Bergson, phenomenology or neurophysiology. Hansen's stance would more likely be welcome by a Marxist thinker like Terry Eagleton, according to whom "the postmodern cult of the socially constructed body, for all of its resourceful critique of naturalism, has been closely linked with the abandonment of the very idea of politics of global resistance" (Eagleton 2000, 111).

\section{References}

Beekman, Rene. 2005. Review of New Philosophy for New Media, by Mark B.N. Hansen. Leonardo vol. 38 no. 4: 355-356.

Bergson, Henri. 1991 [1896]. Matter and Memory. New York: Zone Books.

Bonitzer, Pascal. et al. 2000 [1986]. The Brain is the Screen. An Interview with Gilles Deleuze. In The Brain Is the Screen: Deleuze and the Philosophy of Cinema, ed. Gregory Flaxman, 365-73. Minneapolis: University of Minnesota Press.

Deleuze, Gilles. 2009 [1983]. Cinema 1. The Movement-Image. London: Continuum.

Deleuze, Gilles. 1989 [1985]. Cinema 2. The Time-Image. London: The Athlone Press.

Eagleton, Terry. 2000. The Idea of Culture. Oxford and Malden: Blackwell.

Haines, Christian. 2011. Corporeal Time. The Cinematic Bodies of Arthur Rimbaud and Gilles Deleuze. Angelaki vol. 16 no. 2: 103-126.

Hansen, Mark B.N. 2009. Living (with) Technical Time. From Media Surrogacy to Distributed Cognition. Theory, Culture \& Society vol. 26 no. 2-3: 294-315. Hansen, Mark B.N. 2006 [2004]. New Philosophy for New Media. Cambridge: MIT Press. 
Manovich, Lev. 2001. The Language of New Media. Cambridge and London: The MIT Press.

Marks, Laura U. 2000. The Skin of the Film. Intercultural Cinema, Embodiment, and the Senses. Durham and London: Duke University Press.

Massumi, Brian. 2002. Parables for the Virtual. Movement, Affect, Sensation. Durham and London: Duke University Press. 